\title{
HUBUNGAN PENGETAHUAN DAN SIKAP IBU SERTA DUKUNGAN KELUARGA TERHADAP PEMANFAATAN PELAYANAN ANTENATAL
}

\section{THE RELATIONSHIP OF MOTHER'S KNOWLEDGE AND ATTITUDE AND FAMILY SUPPORT TO THE UTILIZATION OF ANTENATAL SERVICES}

\author{
Lilik Ariyanti ${ }^{1}$, Priyadi Nugroho $\mathbf{P}^{2}$, Martha Irene Kartasurya ${ }^{3}$ \\ lilikariyanti.ariyanti@gmail.com \\ ${ }^{1}$ Program Studi Fisioterapi, STIKES Nasional, Surakarta \\ 2,3Fakultas Kesehatan Masyarakat, Universitas Diponegoro, Semarang
}

\begin{abstract}
Abstrak
Tingginya angka kematian ibu di Indonesia terkait dengan rendahnya pencapaian pelaksanaan Ante Natal Care (ANC). Pencapaian program di Desa Godog masih jauh dibandingkan target yang telah ditetapkan, dimana cakupan $\mathrm{K} 1$ sebesar $68,75 \%$ dan $\mathrm{K} 4$ sebesar $57,14 \%$. Penelitian ini bertujuan menganalisa hubungan faktor pengetahuan dan sikap ibu serta dukungan keluarga dengan pemanfaatan pelayanan antenatal oleh ibu hamil.

Jenis penelitian ini adalah explanatory research dengan desain cross sectional. Pengumpulan data dilakukan dengan wawancara menggunakan kuesioner terstruktur. Sampel penelitian yaitu ibu hamil yang berjumlah 45 orang dengan teknik simple random sampling. Analisis data mengggunakan uji Chi Square dengan taraf signifikansi 5\%. Variabel terikat adalah praktek pemanfaatan pelayanan kesehatan, sedangkan variabel bebas adalah pengetahuan, sikap, dan dukungan keluarga.

Responden di Desa Godog berpengetahuan baik $(46,7 \%)$, mempunyai sikap positif terhadap pelayanan antenatal $(66,7 \%)$ dan mendapat dukungan keluarga $(73,3 \%)$. Hasil penelitian menunjukkan praktek pemanfaatan pelayanan antenatal oleh ibu hamil sebesar 75,6\%. Faktor pengetahuan $(p=0,001)$ dan dukungan keluarga $(p=0,044)$ berhubungan dengan praktek pemanfaatan pelayanan antenatal, sedangkan faktor sikap tidak berhubungan dengan pemanfaatan pelayanan antenatal. Dapat disimpulkan bahwa semakin baik pengetahuan dan adanya dukungan keluarga dapat meningkatkan pemanfaatan pelayanan antenatal
\end{abstract}

Kata Kunci : Ante Natal Care, pemanfaatan pelayanan antenatal

\begin{abstract}
The high maternal mortality rate in Indonesia is related to the low result of the implementation of Ante Natal Care (ANC). The result of the programe in Godog reported is still for compared to the target decided ramely, first visit $K 1$ reported was $68,75 \%$ and fourth visit $K 4$ reported was 57,14\%. This study aimed to determined the relationship of mother's knowledge and attitude and family support to the utilization of antenatal services.

Kind of this research was explanatory research with cross sectional desain. Data collection by structured quesioner interview. Sample of this study are 45 by using simple random sampling technique. Data analysis for relation test used Chi-Square with 5\% significance level. Dependent variable was utilization of health services, and independent variable were knowledge, attitude and family support. The quesioner of knowledge, attitude and family support tested in validitas and reabilitas before.

Respondent in Godog Village had a good knowledge $(46,7 \%)$, positive attitude to antenatal services utilization $(66,7 \%)$ and got family support $(73,3 \%)$. The result showed that antenatal services utilization was about $75,6 \%$. Knowledge $(p=0,001)$ and family support $(p=0,044)$ were significantly associated to antenatal services utilization. Others factor, attitude was not significantly associated. In conclusion that better knowledge and the presence family support could improve the antenatal services utilization.
\end{abstract}

Keywords : Ante Natal Care, antenatal services utilization 


\section{Pendahuluan}

Angka Kematian Ibu (AKI) di Indonesia masih tinggi. Berdasarkan Survei Demografi dan Kesehatan Indonesia (SDKI) survei terakhir tahun 2012, AKI di Indonesia adalah 359 per 100.000 kelahiran hidup (BPS, 2013). AKI Provinsi Jawa Tengah tahun 2016 berdasarkan Profil Dinas Kesehatan Provinsi Jawa Tengah sebesar 109,65 per 100.000 kelahiran hidup. Urutan penyebab kematian ibu di Jawa Tengah dari yang terbanyak adalah perdarahan sesudah persalinan, eklamsi, pre eklamsi, perdarahan sebelum persalinan dan infeksi (Dinas Kesehatan Jateng, 2017).

Faktor lain yang dapat menambah resiko kematian adalah umur ibu yang terlalu muda atau terlalu tua untuk melahirkan, jumlah paritas yang tinggi, jarak antar kehamilan yang pendek, dan kurang lebih 65\% ibu hamil menderita anemia kurang gizi. Menurut Menteri Urusan Pemberdayaan Wanita, menyebutkan faktor lain yang dapat mempengaruhi tingginya AKI adalah faktor pendidikan dan pengetahuan ibu, sosial ekonomi, sosial budaya, geografis, lingkungan dan aksesibilitas ibu hamil pada fasilitas kesehatan modern serta kurangnya tenaga kesehatan dalam memberikan penyuluhan kesehatan pada masyarakat (Depkes, 2012).

Program kesehatan Ibu dan Anak (KIA) diharapkan dapat berperan besar dalam menurunkan AKI. Menurut Profil Dinas Kesehatan Kabupaten Sukoharjo tahun 2014, AKI di Kabupaten Sukoharjo sebesar 100,48 per 100.000 kelahiran hidup. Angka tersebut menunjukkan bahwa AKI di Kabupaten Sukoharjo berada di atas AKI Propinsi Jawa Tengah yaitu 100 per 100.000 kelahiran hidup.

Berdasarkan profil Dinas Kesehatan Kabupaten Sukoharjo tahun 2015, jumlah ibu hamil sebanyak 14.290, dengan kunjungan ke-4 /K4 (92,15\%). Capaian ini berada di dibawah target SPM sebesar $95 \%$, ada penurunan sedikit jika dibandingkan dengan capaian tahun 2014 sebesar $92,26 \%$. Deteksi resiko tinggi ibu hamil tahun 2015 adalah $20 \%$ atau sebanyak 2.860 ibu hamil resiko tinggi (komplikasi kebidanan) dan tertangani 100\%. Diharapkan dengan semakin besarnya cakupan Deteksi resiko tinggi ibu hamil akan dapat segera diambil langkah antisipasi kemungkinan terjadinya kematian. Cakupan kunjungan ibu hamil K4 tertinggi di Kabupaten Sukoharjo adalah Puskesmas Baki $(97,70 \%)$ dan terendah Puskesmas Bulu (80,10\%).

Puskesmas Polokarto merupakan salah satu puskesmas dengan cakupan ibu hamil paling banyak. Hasil Laporan Program KIA Puskesmas Polokarto Tahun 2015, ibu hamil di Desa Godog sebanyak 112 orang, yang memeriksakan kehamilannya ke sarana pelayanan kesehatan yaitu K1 $(68,75 \%)$ dan K4 $(57,14 \%)$. Hasil laporan tersebut di atas masih sangat jauh dari yang diharapkan sesuai dengan Standar Pelayanan Minimal (SPM). Permenkes RI nomor 741/MENKES/PER/VII/2008 tentang Standar Pelayanan Minimal Bidang Kesehatan, Bab II Pasal 2a menyatakan bahwa cakupan kunjungan ibu hamil K4 95\% pada tahun 2015.

Menurut Anderson bahwa faktor-faktor yang menentukan pemanfaatan pelayanan kesehatan dibagi dalam 3 kategori, yakni karakteristik predisposisi, karakteristik pemungkin, dan karakteristik kebutuhan. Karakteristik predisposisi mencakup ciri-ciri demografi, struktur sosial, sikap, keyakinan, dan pandangan individu terhadap pelayanan kesehatan. Karakteristik pemungkin meliputi sumber daya masyarakat (Notoadmodjo, 2010).

Penelitian Situmeang menunjukkan bahwa variabel yang mempunyai pengaruh signifikan terhadap pemanfaatan pelayanan antenatal oleh ibu hamil yaitu variabel pendidikan, pengetahuan, sikap, pendapatan keluarga, dan kondisi ibu. Sedangkan paritas, jarak kelahiran, dan pekerjaan suami tidak memiliki pengaruh terhadap pemanfaatan pelayanan antenatal oleh ibu hamil (Situmeang, 2010).

\section{Metode Penelitian}

Jenis penelitian ini adalah penelitian penjelasan (explanatory research) yaitu penelitian yang menyoroti hubungan antar variabel yang telah ditetapkan dan menguji hipotesa yang telah dirumuskan. Metode penelitian yang digunakan dalam penelitian ini metode survei analitik. Survei analitik merupakan survei atau penelitian yang mencoba menggali bagamana dan mengapa fenomena kesehatan itu terjadi (Notoadmodjo, 2010)

Penelitian ini menggunakan pendekatan cross sectional yaitu mempelajari korelasi antar faktor-faktor risiko dengan efek, dengan cara pendekatan, observasi atau pengumpulan data sekaligus pada suatu saat (point time approach), artinya tiap subyek penelitian hanya diobservasi sekali saja dan pengukuran dilakukan terhadap status karakter atau variabel subyek pada saat pemeriksaan.Jadi pada penelitian ini, peneliti tidak melakukan tindak lanjut.

\section{Pengumpulan Data}

Pengumpulan data dilakukan dengan mencatat data ibu hamil dari kohort ibu, buku KIA dan wawancara menggunakan kuesioner terstruktur. Kuesioner yang terstruktur kemudian 
dilakukan uji validitas dan reabilitas kepada 30 responden dengan kriteria inklusi yang sama dengan subyek penelitian.

Uji validitas dan reabilitas dilakukan untuk menguji pertanyaan dan pernyataan dari variabel pengetahuan, sikap dan dukungan keluarga.

\section{Analisa Data}

Analisa data terdiri dari analisa univariat dan bivariat. Analisa univariat dilakukan untuk mendeskripsikan setiap variabel dengan cara membuat tabel distribusi frekuensi. Uji statistik yang digunakan adalah chi square karena teknik statistik ini digunakan untuk menguji hipotesis bila dalam populasi terdiri dari dua atau lebih kelas dimana data dapat berbentuk nominal ataupun ordinal dan sampelnya besar.

\section{Hasil dan Pembahasan}

Pelayanan kesehatan adalah setiap upaya yang diselenggarakan sendiri atau secara bersamasama dalam suatu organisasi untuk memelihara dan meningkatkan kesehatan, mencegah dan menyembuhkan penyakit serta memulihkan kesehatan perorangan, keluarga , kelompok, dan masyarakat.Pemeriksaan kehamilan merupakan salah satu dari empat standar yang disusun melalui program jaminan mutu dalam Proyek Community Health and Nutrition III Provinsi Jawa tengah (Koentjoro, 2007). Pelaksanaan pemeriksaan kehamilan dilakukan minimal 4 kali oleh ibu hamil yaitu satu kali pada trimester I, satu kali pada trimester II dan 2 kali pada trimester III. Dalam penelitian ini, dikatakan memanfaatkan pelayanan kesehatan bila ibu hamil memeriksakan kehamilannya ke petugas kesehatan sesuai standar.

Pemeriksaan kehamilan termasuk pelayanan kesehatan yang dapat dimanfaatkan ibu hamil. Pemeriksaan kehamilan banyak memberikan manfaat pada ibu hamil, yaitu memantau kemajuan kehamilan untuk memastikan kesehatan ibu dan tumbuh kembang janin,mengenali secara dini adanya komplikasi yang mungkin terjadi selama kehamilan, termasuk riwayat penyakit secara umum, kebidanan dan pembedahan, sehingga dapat mempersiapkan persalinan cukup bulan, melahirkan dengan selamat dan dapat menghindari trauma persalinan seminimal mungkin, mempersiapkan ibu agar masa nifas berjalan normal dan pemberian ASI Eksklusif, dan mempersiapkan peran ibu dan keluarga dalam menerima kelahiran bayi agar dan tumbuh dan perkembangannya berjalan normal (Saifudin, 2006)
Tabel I. Distribusi frekuensi pengetahuan, sikap dan dukungan keluarga berdasarkan pemanfaatan pelayanan kesehatan

\begin{tabular}{lccc}
\hline \multirow{2}{*}{ Karakteristik } & \multicolumn{2}{c}{ Pelayanan antenatal } & \\
\cline { 2 - 3 } & $\begin{array}{c}\text { Tidak } \\
\text { memanfaatkan }\end{array}$ & Memanfaatkan & Jumlah \\
\hline Pengetahuan ibu & 61,5 & 38,5 & 100 \\
$\quad$ Kurang & 0 & 100 & 100 \\
$\quad$ Cukup & 14,3 & 85,7 & 100 \\
$\quad$ Baik & & & \\
Sikap ibu & 30 & 70 & 100 \\
$\quad$ Positif & 13,3 & 86,7 & 100 \\
$\quad$ Negatif & 50 & 12 & 100 \\
Dukungan Keluarga & & 33 & 100 \\
$\quad$ Tidak mendukung & 5,2 & 3 & \\
$\quad$ Mendukung & & & \\
\hline
\end{tabular}

Penelitian ini menunjukkan bahwa pengetahuan berhubungan dengan pemanfaatan pelayanan antenatal berdasarkan uji Chi Square dengan nilaip sebesar $0,001(\mathrm{p}<0,05)$. Ibu yang berpengetahuan baik $(85,7 \%)$ memilih memanfaatkan pelayanan kesehatan dengan memeriksakan kehamilannya sesuai umur kehamilan daripada ibu yang berpengetahuan kurang $(38,5 \%)$.

Pengetahuan atau kognitif merupakan domain yang sangat penting untuk terbentuknya tindakan seseorang (Notoadmodjo, 2010). Ibu hamil dapat menambah pengetahuannya dengan membaca buku KIA yang diberikan oleh bidan. Di dalam buku KIA berisi tentang informasiinformasi yang perlu diketahui ibu selama hamil agar kehamilannya sehat.

Perilaku yang didasari oleh pengetahuan dan kesadaran akan berlangsung lebih lama. Dengan demikian faktor pengetahuan ini sangatlah penting. Biasanya ibu hamil yang berpendidikan lebih tinggi cenderung mempunyai pengetahuan lebih baik sehingga mereka akan lebih mudah menerima informasi tentang kesehatan dari media cetak ataupun media elektronik seperti televisi dan radio (Notoatmodjo, 2010)

Dukungan sangat mempengaruhi perilaku seseorang. Dukungan dapat menguatkan niat seseorang untuk mencari pelayanan antental. Khususnya dukungan dari orang terdekat, misalnya keluarga ataupun teman (Notoatmodjo, 2010). Hasil penelitian ini menunjukkan bahwa dukungan keluarga dapat meningkatkan pemanfaatan pelayanan antenatal. Keluarga responden sebagian besar mendukung ibu untuk periksa hamil di tenaga kesehatan. Ibu yang tidak memanfaatkan pelayanan antenatal adalah ibu yang tidak mendapat dukungan keluarga $(50 \%)$ sedangkan ibu yang mendapat dukungan keluarga, memanfaatkan pelayanan antenatal $(84,8 \%)$. 
Dukungan keluarga sangat penting bagi ibu hamil. Dukungan merupakan salah faktor yang mempengaruhi kehamilan karena berperan dalam psikologis ibu selama hamil.Selain faktor dukungan keluarga, faktor fisik dan faktor lingkungan juga mempengaruhi kehamilan (Sulistyawati, 2009).

Dengan adanya dukungan, dapat memotivasi ibu untuk lebih giat memeriksakan kehamilannya ke tenaga kesehatan. Dukungan ini dapat berupa kesiapan finansial, dukungan informasi serta dukungan psikologis seperti menemani saat periksa hamil. Jadi dukungan keluarga ini berhubungan dengan pemanfaatan pelayanan antenatal. Hal ini sesuai dengan penelitian Pasaribu yaitu dukungan keluarga dapat meningkatkan kunjungan pemeriksaaan kehamilan.

\section{Simpulan}

Pengetahuan berhubungan dengan pemanfaatan pelayanan antenatal oleh ibu hamil. Semakin baik pengetahuan ibu tentang pelayanan kesehatan dan pemeriksaan kehamilan, maka semakin sering memanfaatkan pelayanan antenatal. Sikap tidak berhubungan dengan pemanfaatan pelayanan antenatal oleh ibu hamil. Dukungan keluarga berhubungan dengan pemanfaatan pelayanan antenatal oleh ibu hamil. Semakin baik dukungan keluarga pada ibu hamil, maka ibu hamil semakin termotivasi untuk melakukan pemeriksaan kehamilan ke tenaga kesehatan.

\section{Ucapan Terima Kasih}

Terima kasih dan penghargaan yang tinggi dan mendalam penulis tujukan kepada keluarga dan rekan sejawat yang selalu memberikan dukungan, nasihat dan bimbingan dalam penyelesaian karya ini.

\section{Daftar Pustaka}

BPS. 2013. Survei Demografi dan Kesehatan Indonesia 2012, Calverton, Maryland, USA:BPS and Macro International.

Depkes RI. 2012. Pedoman Pelayanan Kebidanan Dasar. Jakarta: Dirjen Binkesmas

Dinas Kesehatan Jawa Tengah. 2017. Profil Kesehatan Provinsi Jawa Tengah Tabun 2016. Semarang

Koentjoro, Tjahjono. Regulasi Kesehatan di Indonesia. Penerbit Andi: Yogyakarta; 2007

Notoatmodjo, Soekidjo. Ilmu Perilaku Kesehatan. Jakarta: Rineka Cipta; 2010

Notoadmodjo, Soekidjo. Metodologi Penelitian Kesehatan. Jakarta: Rineka Cipta; 2010

Notoatmodjo, Soekidjo. Pendidikan dan Perilaku Kesehatan. Jakarta:RinekaCipta; 2010

Saifuddin, A.B. Buku Acuan Nasional Pelayanan Kesehatan Maternal dan Neonatal. Jakarta: YBP-SP; 2010

Situmeang, Riris. Pengarub Faktor Predisposisi, Faktor Pemungkin dan Faktor Kebutuban Terbadap Pemanfaatan Sarana Pelayanan Antenatal oleb Ibu Hamil di Kelurahan Pasir Bidang Kecamatan Sarudik Kabupaten Tapanuli Tengah tabun 2010. Skripsi FKM USU. Medan. 2010

Sulistyawati, Ary. Asuban Kebidanan pada Masa Kehamian. Jakarta: Salemba Medika; 2009 